\title{
Structure of Thioviridamide, a Novel Apoptosis Inducer from Streptomyces olivoviridis
}

\author{
Yoichi Hayakawa, Kahori Sasaki, Koji Nagai, Kazuo Shin-ya, Kazuo Furihata
}

Received: September 28, 2005 / Accepted: December 13, 2005

(C) Japan Antibiotics Research Association

\begin{abstract}
A novel apoptosis inducer, thioviridamide, was isolated from an actinomycete identified as Streptomyces olivoviridis. The molecular formula of thioviridamide was determined to be $\mathrm{C}_{56} \mathrm{H}_{93} \mathrm{~N}_{14} \mathrm{O}_{10} \mathrm{~S}_{7}^{+}$from high-resolution FAB-MS. The structure of thioviridamide was analyzed by NMR spectral analysis including a variety of twodimensional techniques. COSY and HMBC experiments revealed the presence of a 2-hydroxy-2-methyl-4oxopentanoyl group and eleven amino acid residues including two novel amino acids, $\beta$-hydroxy- $N^{1}, N^{3}$ dimethylhistidinium and $S$-(2-aminovinyl)cysteine. ${ }^{1} \mathrm{H}-{ }^{13} \mathrm{C}$ long-range correlations observed in the $\mathrm{HMBC}, \mathrm{CT}-\mathrm{HMBC}$ and HMBC-HOHAHA spectra connected the partial structures with seven amide linkages and five thioamide linkages to establish the planar structure of thioviridamide
\end{abstract}

as a unique cyclic peptide.

Keywords thioviridamide, antitumor antibiotics, cyclic peptide, thioamide

\section{Introduction}

In the course of screening for apoptosis inducers in transformed cells, a new active substance, thioviridamide (1, Fig. 1), was isolated from the fermentation broth of an actinomycete identified as Streptomyces olivoviridis. Thioviridamide induced apoptotic cell death selectively in $3 \mathrm{Y} 1$ rat fibroblasts transformed with adenovirus oncogenes. In the preceding paper [1], we have described the

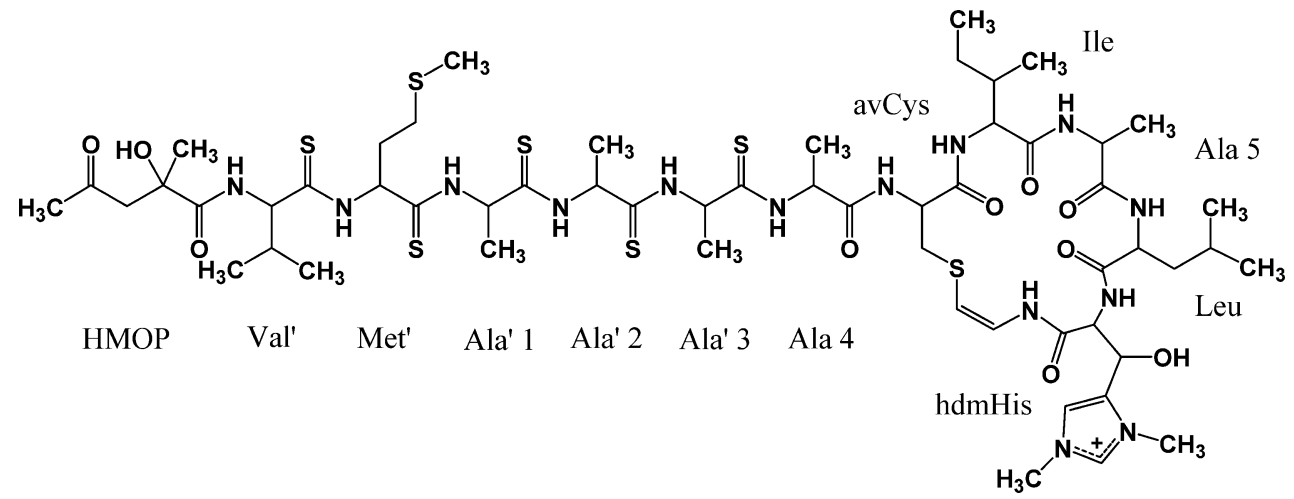

Fig. 1 Structures of thioviridamide (1).

Y. Hayakawa (Corresponding author): Faculty of Pharmaceutical Sciences, Tokyo University of Science, 2641 Yamazaki, Noda, Chiba 278-8510, Japan, E-mail: hykw@rs.noda.tus.ac.jp

K. Sasaki, K. Shin-ya: Institute of Molecular and Cellular Biosciences, The University of Tokyo, Bunkyo-ku, Tokyo 113 0032, Japan
K. Nagai: Fermentation Research Labs., Astellas Pharma Inc., 52-3, Toukoudai, Tsukuba, Ibaraki 305-2698, Japan

K. Furihata: Department of Applied Biological Chemistry, The University of Tokyo, Bunkyo-ku, Tokyo 113-8657, Japan 
Table 1 NMR data summary for thioviridamide in $\mathrm{CD}_{3} \mathrm{OD}$

\begin{tabular}{|c|c|c|c|c|c|}
\hline & $\delta_{\mathrm{C}}$ & $\delta_{\mathrm{H}}(\mathrm{Hz})$ & & $\delta_{\mathrm{C}}$ & $\delta_{\mathrm{H}}(\mathrm{Hz})$ \\
\hline HMOP & & & avCys & & \\
\hline 1 & 180.2 & & 1 & 173.4 & \\
\hline 2 & 75.0 & & 2 & 52.9 & $3.75 \mathrm{~d}(10.5)$ \\
\hline 3 & 53.5 & $3.052 \mathrm{H} \mathrm{s}$ & 3 & 36.4 & $3.21 \mathrm{dd}(12.0,10.5)$ \\
\hline 4 & 212.9 & & & & $2.91 \mathrm{~d}(12.0)$ \\
\hline 5 & 32.4 & $2.243 \mathrm{H} \mathrm{s}$ & 5 & 99.7 & $5.44 d(7.0)$ \\
\hline 2-Me & 27.5 & $1.413 \mathrm{H} \mathrm{s}$ & 6 & 135.0 & $7.30 \mathrm{~d}(7.0)$ \\
\hline Val' $^{\prime}$ & & & Ile & & \\
\hline 1 & 206.0 & & 1 & 174.8 & \\
\hline 2 & 68.8 & $4.50 \mathrm{~d}(4.5)$ & 2 & 63.5 & 3.96 d (10.0) \\
\hline 3 & 33.1 & $2.57 \mathrm{~m}$ & 3 & 37.2 & $1.98 \mathrm{~m}$ \\
\hline 4 & 20.1 & $1.103 \mathrm{H} \mathrm{d}(7.0)$ & 4 & 27.5 & $1.74 \mathrm{~m}$ \\
\hline 5 & 17.4 & $1.003 \mathrm{H} \mathrm{d}(7.0)$ & & & $1.31 \mathrm{~m}$ \\
\hline Met' & & & 5 & 11.1 & $0.993 \mathrm{H} \mathrm{t}(7.0)$ \\
\hline 1 & 205.6 & & 6 & 15.8 & $1.013 \mathrm{H} \mathrm{d}(6.5)$ \\
\hline 2 & 67.3 & $5.59 \mathrm{dd}(8.5,6.0)$ & Ala 5 & & \\
\hline 3 & 33.3 & $2.492 \mathrm{H} \mathrm{m}$ & 1 & 176.2 & \\
\hline \multirow[t]{2}{*}{4} & 31.5 & $2.77 \mathrm{~m}$ & 2 & 53.7 & $4.01 \mathrm{q}(7.0)$ \\
\hline & & $2.63 \mathrm{~m}$ & 3 & 17.4 & $1.443 \mathrm{H} \mathrm{d}(7.0)$ \\
\hline 6 & 14.9 & $2.113 \mathrm{H} \mathrm{s}$ & Leu & & \\
\hline Ala' 1 & & & 1 & 174.9 & \\
\hline 1 & 206.8 & & 2 & 52.8 & $4.02 \mathrm{~m}$ \\
\hline 2 & 64.1 & 5.24 q (7.0) & 3 & 40.5 & $1.472 \mathrm{H} \mathrm{m}$ \\
\hline 3 & 19.9 & $1.593 \mathrm{H} \mathrm{d}(7.0)$ & 4 & 25.8 & $1.71 \mathrm{~m}$ \\
\hline Ala' 2 & & & 5 & 23.8 & $0.843 \mathrm{H} \mathrm{d}(6.5)$ \\
\hline 1 & 207.11 & & 6 & 20.7 & $0.793 \mathrm{H} \mathrm{d}(6.5)$ \\
\hline 2 & 64.5 & 5.24 q (7.0) & hdmHis & & \\
\hline 3 & 20.0 & $1.733 \mathrm{H} \mathrm{d}(7.0)$ & $\mathrm{CO}$ & 167.6 & \\
\hline Ala' 3 & & & $\alpha$ & 58.9 & $4.19 \mathrm{~d}(9.5)$ \\
\hline 1 & 207.08 & & $\beta$ & 62.3 & $6.00 \mathrm{~d}(9.5)$ \\
\hline 2 & 64.5 & $5.30 q(7.0)$ & 2 & 138.7 & $8.77 \mathrm{~s}$ \\
\hline 3 & 20.1 & $1.793 \mathrm{H} \mathrm{d}(7.0)$ & 4 & 135.0 & \\
\hline Ala 4 & & & 5 & 124.1 & $7.66 \mathrm{~s}$ \\
\hline 1 & 174.0 & & $N^{1}-\mathrm{Me}$ & 36.5 & $3.943 \mathrm{H} \mathrm{s}$ \\
\hline 2 & 57.9 & $4.73 q(7.5)$ & $N^{3}-\mathrm{Me}$ & 34.9 & $4.003 \mathrm{H} \mathrm{s}$ \\
\hline 3 & 16.9 & $1.603 \mathrm{H} \mathrm{d}(7.5)$ & & & \\
\hline
\end{tabular}

fermentation, isolation, physico-chemical properties and biological activities of $\mathbf{1}$, as well as the taxonomy of the producing organism. This paper describes the structure elucidation of $\mathbf{1}$.

\section{Results and Discussion}

\section{Structure Elucidation}

The molecular formula of thioviridamide (1) was determined to be $\mathrm{C}_{56} \mathrm{H}_{93} \mathrm{~N}_{14} \mathrm{O}_{10} \mathrm{~S}_{7}^{+}$(ion) from high- resolution FAB-MS ( $\mathrm{m} / \mathrm{z}$ found: 1345.5215, calcd.: 1345.5244). The strong IR absorption peaks at 3350, 1670 and $1530 \mathrm{~cm}^{-1}$ due to amide groups indicated that $\mathbf{1}$ is a peptide antibiotic. The ${ }^{13} \mathrm{C}$ NMR spectrum confirmed the presence of 56 carbons and the heteronuclear multiplequantum coherency (HMQC) [2] spectrum established all one-bond ${ }^{1} \mathrm{H}-{ }^{13} \mathrm{C}$ connectivities (Table 1). COSY and heteronuclear multiple-bond correlation (HMBC) [3] experiments revealed proton spin networks and ${ }^{1} \mathrm{H}-{ }^{13} \mathrm{C}$ long-range correlations as shown in Fig. 2. These data identified two alanine residues (Ala 4, Ala 5), an isoleucine 


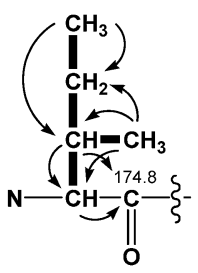

Ile

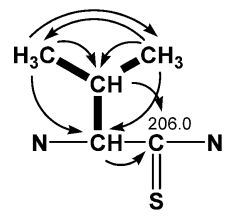

Val'

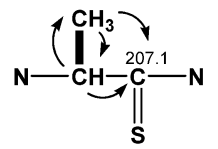

Ala' 3

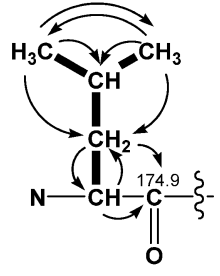

Leu

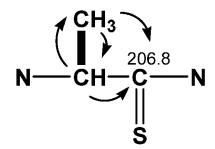

Ala' 1

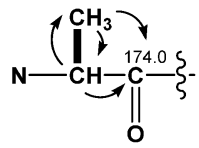

Ala 4

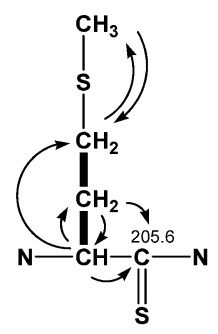

Met'

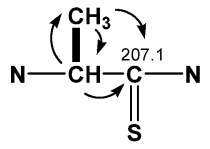

Ala' 2

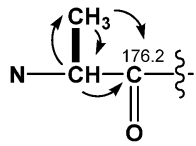

Ala 5
Fig. 2 Amino acid residues in $\mathbf{1}$

Bold lines show ${ }^{1} \mathrm{H}$ spin networks, arrows indicate ${ }^{1} \mathrm{H}-{ }^{13} \mathrm{C}$ longrange correlations.

residue (Ile) and a leucine residue (Leu). Three alaninelike moieties (Ala' 1, Ala' 2, Ala' 3), a valine-like moiety $\left(\mathrm{Val}^{\prime}\right)$ and a methionine-like moiety (Met') contained quaternary carbons $(\delta$ 205.6 207.1), which were assigned to thioamide groups from their chemical shifts (thioacetamide: $\delta$ 207.6) and the molecular formula of $\mathbf{1}$. Acid hydrolysis of $\mathbf{1}$ for amino-acid analysis yielded alanine, valine, isoleucine and leucine in a molar ratio of $3.8: 0.6: 1.0: 1.2$. Neither methionine nor methionine $S$ oxide was detected in the hydrolysate, while ${ }^{13} \mathrm{C}$ NMR data for Met' are closely similar to those of methionine. The lack of methionine and the low recovery of valine and alanine might be ascribed to the resistance of thioamide bonds to acid hydrolysis.

In the $\mathrm{HMBC}$ spectrum, ${ }^{1} \mathrm{H}-{ }^{13} \mathrm{C}$ long-range correlations were observed among two $N$-methyl groups $\left(\delta_{\mathrm{C}} 34.9, \delta_{\mathrm{H}}\right.$ 4.00 and $\left.\delta_{\mathrm{C}} 36.5, \delta_{\mathrm{H}} 3.94\right)$, two aromatic methines $\left(\delta_{\mathrm{C}}\right.$ $138.7, \delta_{\mathrm{H}} 8.77$ and $\left.\delta_{\mathrm{C}} 124.1, \delta_{\mathrm{H}} 7.66\right)$ and an aromatic quaternary carbon $(\delta 135.0)$, indicating the presence of a 1,3-dimethylimidazolium moiety (Fig. 3). This substructure was expanded to include a $\beta$-hydoxy acid due to long-range couplings from an oxymethine proton $(\delta 6.00)$ to the two aromatic carbons $(\delta 135.0$ and 124.1$)$, a methine carbon $(\delta 58.9)$ and a carbonyl carbon $(\delta$ 167.6). These data including the ${ }^{13} \mathrm{C}$ chemical shift of the $\alpha$-methine
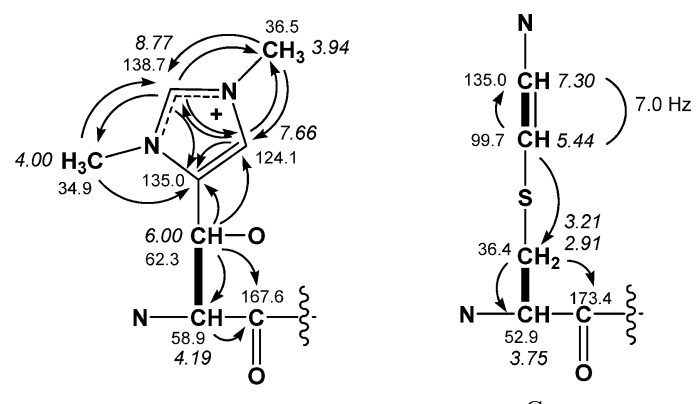

hdmHis

avCys

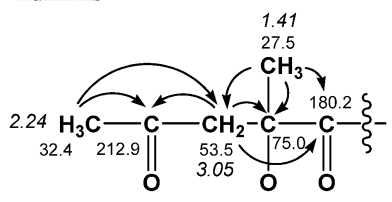

HMOP

Fig. $3 \beta$-Hydroxy- $N^{1}, N^{3}$-dimethylhistidinium (hdmHis), $S$ (2-aminovinyl)cysteine (avCys) and 2-hydroxy-2-methyl-4oxopentanoyl (HMOP) moieties in $\mathbf{1}$.

Bold lines show ${ }^{1} \mathrm{H}$ spin networks, arrows indicate ${ }^{1} \mathrm{H}^{13} \mathrm{C}$ longrange correlations. Plain and italic numbers show ${ }^{13} \mathrm{C}$ and ${ }^{1} \mathrm{H}$ chemical shifts, respectively.

established the structure of a novel amino acid, $\beta$-hydroxy$N^{1}, N^{3}$-dimethylhistidinium (hdmHis). Both the singlet methyl $\left(\delta_{\mathrm{H}} 1.41\right)$ and the singlet methylene $\left(\delta_{\mathrm{H}} 3.05\right)$ were coupled with an oxygenated quaternary carbon $(\delta 75.0)$ and an amide or ester carbonyl carbon $(\delta 180.2)$. An acetyl substituent on the methylene was required by long-range couplings from a singlet methyl $\left(\delta_{\mathrm{H}} 2.24\right)$ to a ketone carbonyl ( $\delta$ 212.9) and the methylene $(\delta 53.5)$, thereby showing the presence of a 2-hydroxy-2-methyl-4oxopentanoyl group (HMOP). In the remaining part, a cysteine-like moiety and a cis olefin were established by NMR data as shown in Fig. 3. A sulfide linkage between the two partial structures was required by a long-range coupling from an olefin proton ( $\delta 5.44)$ to the $\beta$-methylene carbon $(\delta 36.4)$ in the cysteine-like moiety, no coupling between the olefin proton and the $\beta$-methylene protons ( $\delta$ $3.21,2.91)$ and the molecular formula of $\mathbf{1}$ to generate an $S$-(2-aminovinyl)cysteine moiety (avCys).

Five amide bonds between $\mathrm{Val}^{\prime}$ and HMOP, between Ile and avCys, between Ala 5 and Ile, between Leu and Ala 5, and between hdmHis and Leu were identified by threebond couplings from $\alpha$-methine protons to amide carbonyl carbons (Fig. 4). In this analysis, a CT-HMBC [4] experiment enabled us to distinguish the two overlapping $\alpha$-methine protons (Leu: $\delta$ 4.02, Ala 5: $\delta 4.01$ ). Threebond correlations from $\alpha$-methine protons to thioamide carbons established five thioamide linkages between Ala 4 and Ala' 3, between Ala' 3 and Ala' 2, between Ala' 2 and 

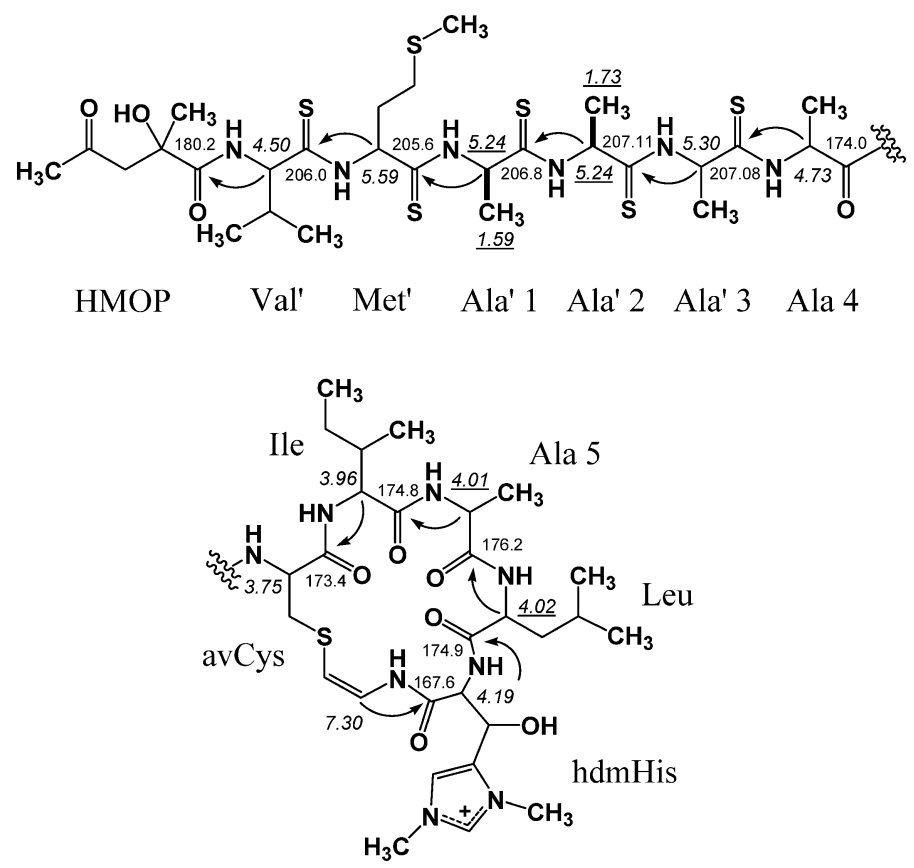

Fig. 4 Amide and thioamide linkages in $\mathbf{1}$.

Arrows indicate ${ }^{1} \mathrm{H}-{ }^{13} \mathrm{C}$ long-range correlations. Plain and italic numbers show ${ }^{13} \mathrm{C}$ and ${ }^{1} \mathrm{H}$ chemical shifts, respectively.

$\mathrm{Ala}^{\prime} 1$, between $\mathrm{Ala}^{\prime} 1$ and $\mathrm{Met}^{\prime}$, and between $\mathrm{Met}^{\prime}$ and $\mathrm{Val}^{\prime}$. Although each $\alpha$-methine proton of Ala' 1 and Ala' 2 was assigned to the same chemical shift $(\delta$ 5.24), an HMBC-HOHAHA [5] experiment revealed four-bond correlations between $\beta$-methyl protons and thioamide carbons by moving the magnetization of $\alpha$-methine protons to the corresponding $\beta$-methyl protons (Ala' $1: \delta 1.59$ and $\mathrm{Ala}^{\prime} 2$ : $\delta$ 1.73). A long-range coupling from an olefin proton $(\delta 7.30)$ to a carbonyl carbon $(\delta 167.6)$ indicated an additional amide linkage between the carbonyl group of hdmHis and the $\varepsilon$-amino group of avCys. The two partial structures thus obtained (Fig. 4) needed to be directly joined from the molecular formula of $\mathbf{1}$. Negative ninhydrin reaction for 1 required an amide linkage between avCys and Ala 4 to establish the planar structure of $\mathbf{1}$ as shown in Fig. 1.

Thioviridamide (1) is a unique cyclic peptide containing five thioamide bonds and novel amino acids, $\beta$-hydroxy- $N^{1}, N^{3}$-dimethylhistidinium (hdmHis) and $S$-(2aminovinyl)cysteine (avCys). Thioamide-containing natural products, (4-methoxyphenyl)- $\mathrm{N}$-methyl-2-oxothioacetamide [6] and cycasthioamide [7] have been isolated from a tunicate Polycarpa aurata and a cycad Cycas revoluta, respectively. Each of these compounds, however, contains only one thioamide group. The unique structural features of thioviridamide combined with its interesting activity make it a possible candidate for anticancer therapeutics and expand the area of natural product chemistry. Stereochemical studies on thioviridamide are in progress.

\section{Experimental}

\section{General}

Mass spectra were measured on a JEOL HX-110 spectrometer in the FAB mode using $m$-nitrobenzyl alcohol as matrix and polyethylene glycol as internal standard. IR spectra were recorded on JASCO FT/IR-470plus spectrometers. NMR spectra were obtained on a JEOL JNM-A500 spectrometer or a Varian INOVA 500 spectrometer with ${ }^{1} \mathrm{H}$ NMR at $500 \mathrm{MHz}$ and with ${ }^{13} \mathrm{C}$ NMR at $125 \mathrm{MHz}$. Chemical shifts are given in ppm using TMS as internal standard. HMQC and HMBC spectra were measured using pulse field gradient programs.

\section{Amino Acid Analysis}

A $6 \mathrm{M} \mathrm{HCl}$ solution of $1(2.4 \mathrm{mg})$ was heated at $110^{\circ} \mathrm{C}$ for 24 hours. After evaporating, the residue was dissolved in $25 \mathrm{ml}$ of water, and $50 \mu \mathrm{l}$ of the solution were analyzed using a Hitachi 835 amino-acid analyzer.

Acknowledgements This work was supported in part by a Grant-in-Aid for Scientific Research, The Ministry of Education, Science, Sports and Culture, Japan. 


\section{References}

1. Hayakawa Y, Sasaki K, Adachi H, Furihata K, Nagai K, Shin-ya K. Thioviridamide, a novel apoptosis inducer in transformed cells from Streptomyces olivoviridis. J Antibiot 59: 1-5 (2006)

2. Summers MF, Marzilli LG, Bax A. Complete ${ }^{1} \mathrm{H}$ and ${ }^{13} \mathrm{C}$ assignments of coenzyme B12 through the use of new twodimensional NMR experiments. J Am Chem Soc 108: 4285-4294 (1986)

3. Bax A, Summers MF. ${ }^{1} \mathrm{H}$ and ${ }^{13} \mathrm{C}$ assignments from sensitivity enhanced detection of heteronuclear multiplebond connectivity by multiple quantum NMR. J Am Chem
Soc 108: 2093-2094 (1986)

4. Furihata K, Seto H. Constant time HMBC (CT-HMBC), a new HMBC technique useful for improving separation of cross peaks. Tetrahedron Lett 39: 7337-7340 (1998)

5. Furihata K, Seto H. HMBC-COSY and HMBC-HOHAHA, new application of HMBC method. Abstract Papers of 15th NMR Symposium 5 8 (1992)

6. Abas SA, Hossain MB, van der Helm D, Schmitz FJ, Laney M, Cabuslay R, Schatzman RC. Alkaloids from the Tunicate Polycarpa aurata from Chuuk Atoll. J Org Chem 61: 2709-2712 (1996)

7. Pan M, Mabry TJ, Beale JM, Mamiya BM. Nonprotein amino acids from Cycas revoluta. Phytochemistry 45: 517-519 (1997) 